\title{
Russian rocket offer holds key to Cluster relaunch
}

[MUNICH] Plans for a relaunch of the European Space Agency (ESA)'s Cluster mission, which was destroyed last summer when its Ariane-5 rocket exploded, now appear to hinge on an offer from the launch company Arianespace to arrange a cheap launch on a Russian rocket.

The mission had been designed to use four satellites to study the solar wind and the Earth's magnetosphere. Shortly before a meeting of ESA's science programme committee last week, it seemed likely that the agency and its member states would be unable to agree a deal for a relaunch. The agency had been unable to persuade Arianespace to provide a cheap launch on the grounds of the company's responsibility for the Ariane- 5 explosion. And the three most crucial member states - Britain, France and Germany - had said they were unable to pay for replacement scientific instruments.

But, only a few hours before last week's meeting, Arianespace presented a new offer, to use two Russian Soyuz launchers rather than Arianes. That would bring ESA's share of the mission's costs within the agreed limit of ECU210 million (US\$184 million) for the satellites and launch.

The ESA committee agreed to give Arianespace and the space agency one month to study the costs and feasibility of the offer. In a reversal of normal practice, it also asked the agency to try to reduce costs further so that the ECU210 million would also pay for the scientific instruments.

If this rather optimistic proposal fails, the mission

could still go ahead - but much later. Cluster's spare satellite, Phoenix, would be launched in any case at the end of this year to carry out part of the mission's scientific programme. The other part of the mission's science - three-dimensional measurements of the magnetosphere - could be revived with the launch of four newly designed mini-satellites. This depends on a full scientific and financial assessment, which ESA is to finance. The assessment will take about a year.

At last week's meeting, the science programme committee was also asked to take note of the space science advisory committee's draft proposals to delay missions in the longterm space science plan, Horizons 2000, to cope with the large budget cuts ESA is facing.

But member states, as represented by their delegates to the committee, were divided in their response. Paul Murdin from Britain's Particle Physics and Astronomy Research Council describes the proposed delays as "unacceptable". He says the advisory committee should adopt a more positive attitude to the budget cuts by investigating "faster, cheaper, better" options, to use the words of NASA, the US space agency.

Lodewijk Woltjer, chairman of the advisory committee and an associate of the Observatoire de Haute Provence in southern France, defends the committee's position. "All we did was add up the numbers, and they added up to trouble," he says. "If Europe doesn't want to pay for a proper space science programme, then we have no choice but to delay missions." But he adds: "If people want to fantasize otherwise, we can't stop them."

Alison Abbott

\section{Germany may relax animal experiment rules}

[MUNICH] The German cabinet last week agreed changes in legislation on animal welfare which, if approved by parliament, could make life easier for German biologists by reducing bureaucratic requirements.

German laws controlling the use of animals in research are the strictest in Europe. One suggestion agreed by the cabinet is that research protocols using animals that are not approved within three months of submission to regional government offices should be taken as approved; in some regions, the process can at present take up to six months.

Another proposal is that small changes to a protocol required during the course of a research project need be notified only to the authorities, rather than having to go through the full approval procedure.
In contrast to the current rules, which require animals to be killed after each experiment, it would be possible to use an animal for several experiments, provided it is killed after the last one. And a requirement that only qualified veterinary surgeons or zoologists should be permitted to operate on animals will be relaxed, allowing foreign scientists qualified to operate in their home countries to do so in Germany.

Not all the proposed changes would reduce the burden of regulation. For example, the bill containing the proposals says that animal experiments carried out for teaching purposes would have to be supervised continuously by a qualified veterinary surgeon or zoologist, rather than being left partly to technical assistants.

\section{Abbott sues Chiron over 'secrets' in heads of recruits}

[SAN FRANCISCO] In a new and unusual interpretation of the law on trade secrets, the US pharmaceutical company Abbott Laboratories is suing its smaller biotechnology competitor, Chiron, claiming that it has raided the pharmaceutical giant's staff to obtain confidential information.

The complaint, filed in the US District Court in Chicago, alleges that 15 high-level scientific and marketing managers recruited from Abbott will inevitably disclose specialized secret knowledge - whether or not they have done so already - and that Chiron and its subsidiary, Chiron Diagnostics, are liable.

The suit claims that over the past three years Chiron and its subsidiary systematically identified and hired individuals with special knowledge about Abbott's immunoassays for HIV, the hepatitis-B and C viruses, human T-cell leukaemia virus, Chagas disease and cancer. It asks for $\$ 75,000$ in damages and an injunction to prevent Chiron from recruiting Abbott employees for a certain period. After that date, Chiron would be able to hire only a limited number of people from its competitor.

Chiron's spokesman, Larry Kurtz, says his company will vigorously oppose the suit. "We don't feel we or any of our people have done anything wrong," he says, adding that Chiron is very cautious about proprietary information from external sources, as it could affect the company's own patent status. Kurtz says that Chiron requires all new employees to sign agreements that acknowledge the confidentiality of information from other companies, as well as from within Chiron.

Abbott claims that Chiron intentionally hired the employees to obtain trade secrets and proprietary information about technology and processes.

Some legal experts say that companies are increasingly likely to apply the theory of "inevitable disclosure" to competitors that lure away staff with knowledge of company technology, research and marketing.

Judy Brown, a specialist recruitment consultant, argues that recruiters look primarily for technical skills and compatible backgrounds in research staff, not trade secrets.

But Julie J. Furer, an attorney for Sanchez \& Daniels in Chicago who is representing Abbott, says the Abbott case could give recruiters pause for thought when targeting high-level scientists from competing companies. Her firm's arguments are based on similar suits by FMC Corporation, Campbell Soup Company and Pepsico. Pepsico successfully used the argument in 1994 to prevent William E. Redmond Jr from going to work for its rival Quaker Oats.

SallyLehrman 